\title{
Hábito deletério não nutritivo: sucção digital e a consequência mordida aberta
}

\author{
Non-nutritious harmful habit: digital sucking and the consequence of open bite
}

Recebido: 11/05/2021 | Revisado: 16/05/2021 | Aceito: 18/05/2021 | Publicado: 19/05/2021

\author{
Thalya Horsth Maltarollo \\ São Leopoldo Mandic, Brasil \\ E-mail: thalyamaltarollo@gmail.com \\ Rabbith Ive Shitsuka Risemberg \\ University of California, Los Angeles, USA \\ E-mail:rabbith.ive@gmail.com \\ Ariane Cristina da Silva \\ Universidade Brasil, Brasil \\ E-mail: arianecriis9@gmail.com \\ Irineu Gregnanin Pedron \\ Universidade Brasil, Brasil \\ E-mail: igpedron@alumni.usp.br \\ Caleb Shitsuka \\ Universidade Brasil, Brasil \\ E-mail: cashitsuka@gmail.com
}

\begin{abstract}
Resumo
A sucção digital é uma ação que pode ser definido como levar os dedos das mãos até a cavidade bucal, exercendo uma pressão com uma força intensa que pode ocorrer danos aos dentes, como o deslocando, pode ser um sintoma não isolado decorrente de conflitos ou instabilidade emocional, tornando um padrão pessoal de auto-satisfação. Dentre os problemas oclusais originado por hábitos de sucção não nutritiva é comum a mordida aberta anterior. Deste modo o trabalho tem como finalidade avaliar como o hábito oral deletério: sucção digital, interfere na normo oclusão, alterando as características funcionais dos tecidos duros e moles, interferindo no padrão normal de crescimento facial, ocasionando a mordida aberta. Os hábitos orais podem causar inúmeros prejuízos ao crescimento e desenvolvimento do sistema estomatognático. A gravidade dessas alterações está diretamente relacionada a duração, frequência e intensidade do hábito.
\end{abstract}

Palavras-chave: Hábitos; Sucção de dedo; Má Oclusão; Odontopediatria; Mordida aberta.

\begin{abstract}
Digital suction is an action that can be defined as taking the fingers to the oral cavity, exerting pressure with an intense force that can cause damage to the teeth, such as dislocating it, it can be a non-isolated symptom resulting from conflicts or instability emotional, making it a personal standard of self-satisfaction. Among the occlusal problems caused by non-nutritive sucking habits, anterior open bite is common. In this way, the work aims to evaluate how the harmful oral habit: digital sucking, interferes with normal occlusion, changing the functional characteristics of hard and soft tissues, interfering with the normal pattern of facial growth, causing the open bite. Oral habits can cause numerous losses to the growth and development of the stomatognathic system. The severity of these changes is directly related to the duration, frequency and intensity of the habit.
\end{abstract}

Keywords: Habits; Finger sucking; Malocclusion; Pediatric dentistry; Open bite.

\section{Introdução}

Hábito é uma formação adquirida pela repetição de um ato, que se torna inconsciente e passa a ser incluído à nossa personalidade. No entanto, o hábito torna-se um vício quando prejudica o processo de crescimento e desenvolvimento do organismo humano. (Monguilhott et al., 2003)

Quando se relaciona com a cavidade oral, pode se trazer diversas alterações tanto nos tecidos musculares, como dentários e ósseo, surgindo até uma má oclusão. O hábito irá se instalar pelo fato de ser agradável e proporcionar satisfação à criança. Quando a criança tem o hábito bucal deletério até os três anos de idade, pode se ter uma autocorreção, de alguma possível alteração bucal adquirida com o hábito. (Gisfrede et al., 2016) 
A sucção digital é uma ação que pode ser definido como levar os dedos das mãos até a cavidade bucal, exercendo uma pressão com uma força intensa que pode ocorrer danos aos dentes, como o deslocamento, pode ser um sintoma não isolado decorrente de conflitos ou instabilidade emocional, tornando um padrão pessoal de auto-satisfação. Dentre os problemas oclusais originado por hábitos de sucção não nutritiva é comum a mordida aberta anterior. (Piva et al., 2012)

A constante presença do dedo entre os dentes superiores e inferiores impede o correto desenvolvimento vertical dos dentes anteriores e dos processos alveolares nesta determinada região, causando, em muitos casos, a mordida aberta. (Piva et al., 2012)

Sendo assim, o objetivo deste trabalho foi revisar a literatura vigente sobre o hábito bucal deletério, sucção digital e uma consequência, a mordida aberta em Odontopediatria.

\section{Metodologia}

Este trabalho foi realizado por meio de uma revisão bibliográfica de literatura onde foram pesquisados artigos científicos que apresentam conteúdo sobre o habito não nutritivo: sucção digital e sobre a consequência mordida aberta. As bases de dados utilizadas neste trabalho para a seleção dos artigos foram BVS; PubMed, SCIELO e Google Scholar. Os artigos científicos pesquisados para a construção deste trabalho, foram publicados em revistas e jornais nacionais e internacionais de 1990 a 2020 nos idiomas inglês e português totalizando 19 trabalhos.

\section{Revisão da Literatura}

\section{Definição}

Segundo Moyers (1991), um hábito pode ser definido como um estímulo aprendido que, quando praticado, pode tornar-se inconsciente e incorporado à personalidade do indivíduo. Hábito é o resultado da repetição de um ato com determinado fim, tornando-se com o tempo resistente às mudanças. (Silva, 2006)

A boca é a região mais importante do corpo no primeiro ano de vida da criança e a sucção nutritiva é importante para a sobrevivência do recém-nascido, uma vez que instintivamente o conduz à satisfação de suas necessidades nutricionais. A sucção é um reflexo inato, observado antes mesmo do nascimento, na $29^{\circ}$ semana de vida intrauterina, representando o padrão de comportamento mais primitivo e complexo do ser humano. (Góes et al., 2013; Shitsuka et al., 2019)

Durante toda a vida, o crescimento da face é desenvolvido através de diversos hábitos como a mastigação, deglutição, fonação e respiração. Essas funções devem ser normais para o crescimento dos arcos dentários e para o crescimento craniofacial assumam estrutura correta. (Silva, 2006)

A sucção não nutritiva é um habito que consiste em um ato neuromuscular complexo, podendo associar-se com crescimento ósseo modificado ou retardado, más posições dentárias, distúrbios respiratórios, dificuldades na fala, alterações no equilíbrio da musculatura e problemas psicológicos. (Silva, 2006)

O hábito sem fim nutritivo mais frequente encontrado nas crianças é o da sucção digital, ao lado da sucção de chupetas, sendo prevalente nos primeiros anos de vida da criança. Esses dois hábitos estão entre os maiores fatores de risco para o desenvolvimento de más oclusões. (Góes et al., 2013)

Já que existem mecanismos individuais de ajustes no desenvolvimento e alterações de crescimento que podem permitir a evolução normal da oclusão, somente a presença do habito não é determinante para a má oclusão dentaria. Depende da frequência, duração e intensidade de cada criança. ${ }^{6}$

Segundo Almeida et al. (2000) a interrupção do hábito de sucção ainda durante a fase de dentição decídua, favorece a autocorreção de desvios morfológicos da oclusão que, tenham se desenvolvido precocemente. 


\section{Fatores etiológicos}

A etiologia dos hábitos bucais em geral contém um aspecto psicológico muito forte. Muitos pais podem com certa frequência se sentir culpados ou fracassados ao lidarem com os hábitos dos filhos e assim procuram avidamente um meio para a cessação do comportamento indesejável. (Rottmann, 2011)

Parte da responsabilidade do surgimento de hábitos orais viciosos ou deletérios decorre da necessidade de suprir carências afetivas ou neurais de sucção. (Pizzol et al., 2012)

Há basicamente três teorias para explicar a etiologia e o prolongamento dos hábitos de sucção não nutritiva: (Rottmann, 2011)

\section{Teoria da função perdida}

Segundo esta teoria, a sucção insuficiente nos primeiros 24 meses de vida contribui para a formação do hábito. E muitos são os trabalhos que relacionam o tempo de amamentação exclusiva com a prevalência de hábito de sucção não nutritiva: quanto menor o tempo, maior é a presença do hábito. Dificilmente a mãe de hoje em dia reúne condições para realizar uma amamentação adequada, e acaba lançando mão de recursos artificiais como a mamadeira, que deixa passar um fluxo bem maior de leite, fazendo com que a criança atinja em apenas alguns minutos a sensação de plenitude alimentar que, via amamentação natural, levaria cerca de meia hora. Dessa forma o bebe não faz sucções suficientes, procurando assim, um substituto. (Rottmann, 2011)

\section{Teoria Psicanalítica}

Para Freud (1990) a sucção prolongada é um sintoma neurótico de uma perturbação emocional resultante de uma fixação do estado psicossexual da fase oral. Esta teoria afirma que se houver uma frustração das necessidades orais durante a infância, a conduta da criança sofrerá alguma danificação no futuro.

Para a teoria psicanalítica a sucção não nutritiva é normal na criança, sendo cessada por volta dos dois anos de idade. Entre os 2 e 5 anos é considerada uma simples reação a estados de cansaço, doença, frustração, tédio, privação e punição. (Rottmann, 2011)

\section{Teoria do Aprendizado ou Conduta Adquirida}

Contradizendo a teoria psicanalítica, esta teoria diz que a sucção não nutritiva é um simples comportamento aprendido. No início, o comportamento ocorre conscientemente pela satisfação e prazer que proporciona à criança, mas em função da repetição contínua, instala-se um processo de aperfeiçoamento e automatização, originando inconscientemente o hábito propriamente dito. (Rottmann, 2011)

Mas estes não são os únicos fatores desencadeantes de hábitos como dedo ou chupeta. O contexto social apresenta sua influência através de conflitos familiares, pressão escolar, emprego da mãe que colabora com a renda familiar de forma total ou parcial, além da dificuldade de acesso aos serviços odontológicos, algumas doenças respiratórias e problemas de fala, irritações associadas à erupção dental, interferências oclusais, entre outros. (Pizzol et al., 2012; Shitsuka et al., 2020)

De acordo com Piva et al., (2012) a alimentação materna causa fadiga e cansaço muscular na criança devido ao esforço que ela precisa fazer para sugar; em seguida, a criança fica sonolenta, sendo que muitas vezes ela está dormindo ao terminar a amamentação. O orifício dos bicos das mamadeiras geralmente é grande e o leite é ingerido muito rapidamente e não exigem a força de sucção da musculatura. Os autores afirmam que a criança que não é amamentada no seio apresenta uma 
tendência maior de sugar o dedo, como forma de exercitação da musculatura, sendo assim uma como a criança não teve esforço ao se alimentar com a mamadeira ela não fica cansada e assim esta falta de cansaço o induz a sugar seu dedo ou objeto.

Piva et al., (2012) em revisão de literatura descreveram sobre o desenvolvimento infantil e asseguram que os hábitos de sucção não-nutritivos podem ter origem emocional. $\mathrm{O}$ ato de chupar o dedo é utilizado na hora de dormir, ao acordar, em períodos excitantes ou de frustrações para se acalmar. Para os bebês, sugar seu dedo é uma maneira de se manter controlado nos momentos difíceis, sendo o melhor recurso para a criança se acalmar. O dedo é um recurso próprio e natural do bebê que sempre está a sua disposição, o que faz do ato de sucção digital um hábito que, se não moderado, passa a ser nocivo.

Muzulan et al., (2011) relata que a etiologia da mordida aberta anterior é causada pela associação de diversos fatores e está quase sempre relacionada a uma desarmonia miofuncional orofacial, seja por fatores genéticos ou pela ação prolongada de hábitos orais. Crianças que fazem o uso da mamadeira estão mais propensas à sucção digital do que as que receberam aleitamento materno, pois a mamadeira não satisfaz a necessidade que a criança tem de sugar.

\section{Prevalência}

$\mathrm{O}$ ato de sucção digital pode ser definido quando o dedo é levado à boca e exerce pressão com forças intensas o bastante para deslocar dentes e deformar o osso que está em crescimento. É necessário que sejam conhecidos fatores como etiologia, frequência, intensidade, duração do hábito; idade do paciente, posição do dedo na boca, padrão de crescimento da criança, grau de tonicidade da musculatura bucofacial para determinar o comprometimento que pode ser causado. (Piva et al., 2012)

O dedo escolhido preferencialmente é o polegar, mas os outros dedos também estão associados. Esse tipo de sucção gera uma sensação prazerosa e satisfatória na criança e também satisfaz a necessidade nutritiva. (Gisfrede et al., 2016)

\section{Consequência}

Se a sucção digital ainda persistir aos 07 anos de idade ou mais, as deformações da oclusão aumentam significativamente e o equilíbrio muscular existente na região orofacial será afetado com comprometimento também da postura dos lábios, língua e deglutição. Nesses casos, se o hábito não for deixado espontaneamente, deve-se ser feita intervenção profissional para a sua remoção. (Piva et al., 2012)

De acordo com Tanaka et al., (2004), a mordida aberta anterior é a falha de um ou mais dentes para encontrar seus antagonistas na arcada oposta. Com a falta de contato oclusal, os dentes posteriores podem desenvolver uma supraoclusão, enquanto que os incisivos mostram uma infra-oclusão e, devido à geometria das arcadas, 2,0mm de extrusão ou alongamento posterior em molares, abrem a mordida cerca de 4,0mm, contribuindo assim para o desenvolvimento da mordida aberta anterior, que deste modo pode ser dividida em mordidas abertas simples, que são restritas aos dentes e ao processo alveolar, e mordidas abertas complexas, que se caracterizam principalmente na displasia esquelética vertical - as chamadas mordidas abertas esqueléticas.

\section{Tratamento}

Vasconcelos et al., (2009) sugerem que para a remoção dos hábitos de sucção, a criação de politicas que envolvam o esclarecimento da família do paciente, já que a sua erradicação precoce depende do envolvimento familiar, o que pode ser alcançado através de campanhas educativas que promovam a saúde integral do indivíduo.

A participação familiar é muito importante na tentativa da criança abandonar o hábito, pois o método mais aconselhável para a remoção do hábito é a motivação sem uso de chantagens psicológicas. Incentivar e motivar a criança são 
fundamentais; com essa finalidade, pode-se apresentar o problema à criança podendo ser desenvolvidas atividades lúdicas. Em algumas situações, uma conversa franca entre a criança e o profissional é suficiente. (Piva et al., 2012)

Uma das soluções para a remoção hábito de sucção é ao uso de aparelho intrabucal fixo com grade palatina em casos de sucção digital, e associação de acompanhamento psicológico com uma terapeuta. Outra forma seria a conscientização da criança pelo profissional sobre como o hábito se instala, quais as suas consequências e sequelas, tendo como auxílio as fotografias, modelos e diapositivos do próprio paciente, além da orientação aos pais, de modo que os utilizem em casa. Criar atividades que despertem a atividade da criança como a simulação em bonecos, desenho nos dedos. De acordo com os mesmos, o hábito é prazeroso, mas se ocorrer a substituição por momentos em família facilita a sua remoção. (Martins et al., 2010)

Para Monguilhott et al., (2003) a grande maioria dos casos, torna-se inevitável recorrer aos aparelhos mecânicos para interromper o hábito de sucção. Dentre os aparelhos para impedir o hábito, o mais comumente usado é a grade palatina como citado pelo autor anterior, que pode ser fixa ou removível, juntamente com um arco de Hawley com a finalidade de melhorar o posicionamento dos incisivos, sendo que existe preferência pela fixa já que não depende da cooperação do paciente para o seu uso. (Monguilhott et al., 2003)

O tratamento da fase de dentadura decídua envolve principalmente o controle hábitos nocivos e atendimento multiprofissional com fonoaudiólogo, otorrinolaringologista e ortodontista (Maia et al., 2008)

\section{Discussão}

O trabalho de revisão da literatura aponta para uma relação dos hábitos orais deletérios, associados a alterações anatômicas e fisiológicas de estruturas da face. Além disso, esses também são citados como preditores capazes de modificar o padrão de comportamento da criança no que tange a sua nutrição, como Gisfrede et al., (2016) e Muzulan et al., (2011) que observaram correlação entre sucção do dedo e interrupção do aleitamento materno exclusivo, como consequência atribuída a "confusão de bicos" que seria gerado no lactente.

Segundo Piva et al., (2012), hábitos de sucção entre 18 e 24 meses são considerados dentro da normalidade, após esse período, o uso prolongado poderá trazer risco as estruturas craniofaciais.

Segundo Silva et al., (2006), em estudo com 261 crianças de 6 a 12 anos, 58,7\% apresentaram maloclusão. Apesar do resultado, para se estabelecer um diagnóstico entre hábitos deletérios e maloclusão, é necessário a análise da intensidade, duração e frequência (Tríade de Graber). Estudos de Goés MPS (2003) realizado por meio de questionário com responsáveis de 524 crianças em 17 centros educacionais públicos de Recife/PE teve uma prevalência em relação ao hábito de sucção digital foi verificado que das 50 crianças que iniciaram o hábito, $45(90,2 \%)$ permaneceram com ele por pelo menos 36 meses de idade. Esses resultados apontam para uma baixa prevalência do habito de sucção digital, mas também, para uma maior dificuldade na remoção deste hábito quando instalado.

De acordo com os resultados de Pizzol et al., (2011) os hábitos foram mais prevalentes no gênero feminino (55\%) e na faixa etária entre seis meses e dois anos. O hábito mais comumente encontrado foi o de sucção chupeta, seguido pela sucção de mamadeira e sucção digital (7,6\%), não havendo associação entre o tipo de hábito e condição socioeconômica. Das crianças participantes, $1.239(90,4 \%)$ receberam aleitamento materno, sendo que o tempo de maior prevalência de amamentação foi entre seis meses e 12 meses (43\%), não necessariamente de forma exclusiva, mas por um período igual ou superior ao preconizado pela OMS. Houve associação entre o tempo de amamentação com a presença e o tipo de hábito, visto que as crianças que receberam o aleitamento natural por um período superior a 12 meses tenderam a não desenvolver hábitos deletérios. Os resultados comprovam que quanto maior é o tempo de amamentação, menor é a prevalência de hábitos. 
Para a Rottmann et al., (2012), métodos de tratamento ou colocação de dispositivos mecânicos sem a aceitação da criança irá provocar um desajuste psicológico de grandes dimensões, causando danos irreversíveis à sua personalidade. O uso de métodos punitivos como o uso de esmaltes com gosto ruim, ridicularização da criança, negação de privilégios e humilhação não são eficazes e só causam frustração. Os métodos "negativos” de remoção do hábito só estimulam a criança a desejar mais ainda sucção.

Tanto o profissional como os pais têm papéis fundamentais nesta tarefa: o profissional deve atuar na motivação da criança por meio de slides, modelos ou fotos de dentes bonitos e feios para tentar se explicar à criança quais as consequências de seus hábitos. É importante que no modelo de ensino Odontológico seja de forma remota ou presencial, os estudantes recebam essa orientação para que sejam aplicadas na prática profissional. (Fernandes, et al., 2020; Rocha, et al., 2020; Santo, et al., 2016; Camacho, et al., 2020)

A participação dos pais é muito importante, em casa reforçando tudo o que for dito pelo profissional no consultório, de maneira que todos utilizem a mesma linguagem. É importante uma atitude positiva em relação às realizações dos filhos, pois pais ansiosos acabam intensificando o hábito da criança.

\section{Conclusões}

Os hábitos orais podem causar inúmeros prejuízos ao crescimento e desenvolvimento do sistema estomatognático. A gravidade dessas alterações está diretamente relacionada a duração, frequência e intensidade do hábito. Portanto, torna-se necessária uma abordagem multidisciplinar para que se tenha sucesso na remoção desses hábitos, visto que não se trata apenas de um processo mecânico e funcional, devendo-se considerar as implicações emocionais para as crianças e para os pais.

Com base na revisão de literatura, nota-se que a quantidade de estudos existentes atualmente é baixa, sendo necessário que mais estudos sejam realizados para que seja possível obter mais embasamento no assunto, viabilizando assim métodos para interrupção de hábitos deletérios.

\section{Referências}

Almeida RR, Pedrin RRA, Almeida MR, Garib DG, Almeida PCMR, Pinzan A. Etiologias das más oclusões: causas hereditárias e congênitas, adquiridas gerais, locais e proximais (hábitos bucais). Rev. dent. pressortodon. ortop. Maxilar. 2000 nov-dez.;5(6):107-29.

Camacho, A. C. L. F.; et al., A tutoria na educação à distância em tempos de COVID-19: orientações relevantes. Research, Society and Development, [S. l.], v. 9, n. 5, p. e30953151, 2020. DOI: 10.33448/rsd-v9i5.3151.

Fernandes, S. M et al., O ensino a distância no Brasil: alguns apontamentos. Research, Society and Development, [S. l.], v. 9, n. 1, p. e21911551, 2020. DOI: 10.33448/rsd-v9i1.1551.

Freud S.- Obras completas de Sigmund Freud. Edição Standard Brasileira, Rio de Janeiro, Imago, 1987. Friman, P.C.; Leibowitz, M. An effective and 12 acceptable treatment alternative for chronic thumb-and finger sucking. J Ped Psychol, 1990; v.15, n.1, p.57-65.

Gisfrede T, Kimura J, Reyes A, Bassi J, Drugowick R, Matos R, Tedesco T. Hábitos bucais deletérios e suas consequências em Odontopediatria. Rev. bras. odontol. 2016 abr./jun.; 73(2): 144-9.

Góes MPS, Araújo CMT, Góes PSR. Persistência de hábitos de sucção não nutritiva: prevalência e fatores associados. Rev. Bras. Saúde Matern. Infant., Recife, jul. / set., 2013.; 13 (3): 247-257

Maia, S.Aet al., Diferentes abordagens no tratamento da mordida aberta anterior. Com Scientia e Saúde. 2008v.7, n.1, p. 7782. 
Martins B, Dadalto E, Gomes A, Sanglard L, Valle M. Métodos usados para remoção dos hábitos de sucção de dedo e/ou chupeta em crianças do município de Mutum-MG. Revista Brasileira de Pesquisa em Saúde. 2010; 12(4): 19-25.

Monguilhott L, Frazzon J, Cherem V. Sucking Habits: how and when to treat it in a orthodontic x fonoaudiology view. R Dental Press Ortodon Ortop Facial. 2003 jan./fev.; 8(1): 95-104. 11

Moyers, RE. Etiologia da má oclusão. In: MOYERS, RE .Ortodontia .3. ed. Rio de janeiro: Koogan, 1991. p.127-140.

Muzulan CF, Gonçalves MIR. O lúdico na remoção de hábitos de sucção de dedo e chupeta. Parana. J Soc Bras Fonoaudiol. 2011 out.; 23(1):66-70.

Piva R, Werneck R I; Pereira L P; Dos Reis A O; Amorim G C. O tsb na remoção de hábitos de sucção. Revista Gestão \& Saúde. 2012; 4(2): 15-21.

Pizzol KEDC, Montanha SS, Fazan ET, Boeck EM, Rastelli ANS. Prevalência dos hábitos de sucção não nutritiva e a sua relação com a idade, gênero e tipo de aleitamento em pré- escolares da cidade de Araraquara. Rev. CEFA. 2012 maio/jun; 14(3): 506-515.

Rocha, S. S. D. et al., A Educação a Distância na era digital: tipologia, variações, uso e possibilidades da educação online. Research, Society and Development, [S. l.], v. 9, n. 6, p. e10963390, 2020. DOI: 10.33448/rsd-v9i6.3390.

Rottmann RW. Introduction of a motivational method to discontinue nonnutricional sucking habit. Literature review and case report. Journal of Biodentistry and Biomaterials mar./ago. 2011; 1: 49-60

Santo, E. do E. Ensinar e aprender na Educação a Distância: um estudo exploratório na perspectiva das práticas tutoriais. Research, Society and Development, [S. l.], v. 3, n. 2, p. 92-114, 2016. DOI: 10.17648/rsd-v3i2.16.

Shitsuka R., et al., Comparação de técnicas cirúrgicas para dentes com atraso na erupção. E-Acadêmica. 2020.1 (1) e13. Recuperado de https://eacademica.org/eacademica/article/view/13

Shitsuka, C. et al., Influência dos pais sobre o comportamento infantil no atendimento odontológico. Research, Society and Development, [S. l.], v. 8, n. 7, p. e43871154, 2019. DOI: 10.33448/rsd-v8i7.1154.

Silva EL. Hábitos bucais deletérios. Rev Para. Med. 2006 jun.;20(2):47-50

Tanaka O, Kreia TB, Bezerra J de GB, Maruo H. A má-oclusão e o hábito de sucção de diferentes dedos. J Bras Ortodon Ortop Facial. 2004; 9(51):276- 83

Vasconcelos F, Massoni A, Ferreira A, Katz C, Rosenblat A. Ocorrência de Hábitos Bucais Deletérios em Crianças da Região Metropolitana do Recife, Pernambuco, Brasil. Pesq Bras Odontoped Clin Integr. 2009 set./dez.; 9(3): 327-32. 